\title{
The Impact of Government Supervision and Consumer Purchasing Behavior on Food Safety
}

\author{
Yuan Chen, Xiaogang Tang, Kangyu Chen, Hui Liu \\ School of Economics \& Commerce, Guangdong University of Technology, Guangzhou, China \\ Email:86436078@qq.com
}

Received 20 August 2014

\begin{abstract}
This paper aims at the theoretical analysis to the impact of government supervision and consumer purchasing behavior on food quality security, so as to look for safety strategies and measures to strengthen and improve the level of food safety in China. Reputation mechanism is introduced and Bayesian approach is based on, in which government supervision as well as consumer purchasing behavior is taken as crucial factors to impact on the food quality security. As to the proposed quantitative indicators, government supervision includes exposure rate, fine and etc.; at the same time, consumer purchasing behavior includes consumer's WTP for security food and consumer expectations to food safety. Taking China's dairy industry as an example, it makes simulation by Netlog. The results show that consumer purchasing behavior alone has little effect on the dairy companies' decision-making to be honest or counterfeiting enterprises. However, combination government supervision with purchasing behavior has great impact, and plays very good effects on food safety.
\end{abstract}

\section{Keywords}

Food Safety, Reputation Mechanism, Government Supervision, Customer's Willingness to Pay

\section{Introduction}

From 2002 to 2007, the annual development speed of dairy industry in China was over 20\%. After the accident occurrence of Sanlu infant formula contaminated by melamine in 2008, the speed has been decreased to $8.89 \%$ during 2008-2013 [1]. Food quality safety accidents impact dairy industry greatly and lead customers far away from domestic dairy market. Problem in dairy industry is just a miniature of Chinese food safety.

Guarantee to food security is one of the fundamental roles of government; and consuming safe food is one of the consumers' basic rights rather than privilege, although consumers have willingness to pay higher price for safe food [2]. Recent studies show food safety concerns at an all-time high for Chinese consumers [3]. It is important for Chinese government and product marketers to understand consumer awareness of food safety issues and their preferences for safety and quality attributes [4]. But little focus has been given to the impact of con- 
sumers' purchasing behavior on food safety, especially combined with government supervision measures.

The concept of Willingness to Pay (WTP) was defined as the maximum price that a given consumer accepts to pay for a product or service. It was designed to determine prices for pure public goods and service, and is still used for subjects as varied as the value of human life or minimization of risks threatening human life [5]. So, we define Consumer's WTP for food safety as consumer's willing to pay an extra price for buying safety food. This concept is important because it could directly nourish pricing decisions and influence producers' earning, and further influence diary producer's decision to produce safe food or food of inferior quality.

Consumer expectations can be interpreted as the wish of the consumers on the product or service they consumed or enjoyed [6]. So, consumer expectations to food safety of diary enterprises can be defined as the wish of the consumers on the food safety to the diary products they consumed. This concept determines the purchase probability of consumers, and will affect the demand of safe diary product in the market, then further affect the market price of safe diary product.

Reputation is indicative of the confidence placed in a system or of entity's ability to deliver desired results. Reputation systems are intended to aggregate and disseminate feedback about participants' past behavior and considered as a means to distinguish honest sellers from dishonest ones [7]. In asymmetric information market, the game to be honest or dishonest will lead to reputation effect. Without this mechanism, dishonest sellers might drive out honest ones, leading to a kind of market failure [8].

No doubt, many food safety incidents were caused by profit-driven firm behavior [3]. Food markets often have asymmetric information problems: the producer has private information about food characteristics whereas consumers only have a vague idea. The producers try to set up reputation at first, and then some of them try to play game strategy to share the prior reputation in later sales of inferior quality products so as to get more benefit. In this case, the variation in quality of goods is a result of deliberate management decisions. The change in quality will necessarily lead to variation in reputation [9]. The sharing of reputation seriously lowers the holistic industry's ability to get back the reputation and the holistic industry's benefit in the future [10].

Probabilistic/Bayesian models directly model the dynamic statistical interaction between consumers and producers through the index of consumer expectations. Reference [11] computes the reputation scores based on Bayesian models, the advantage of which is that they provide a sound theoretical basis for computing reputation scores. Reference [7] introduces a probabilistic model which accounts for truncation of ratings of reputation and a Bayesian model assuming a prior distribution on the parameters. Expectation-maximization algorithm is also developed in the model.

The idea behind reputation systems is that even if the consumer can not try the product in advance, he can be confident that it will be what he expects as long as he trusts the producer. Based on reputation mechanism, this paper establishes mathematic model to do simulation research on different food safety strategies' effects on dairy enterprises.

\section{Theoretical Model}

Assume two kinds of food producers, honest enterprises (enterprise $h$ ) who always provide safe food and counterfeiting enterprises (enterprise $c$ ) who play different game strategy in different period $(t=1,2, \cdots, n)$ of sales and sometimes provide problematic food so as to share the reputation to get more benefit, produce 3 versions of a food, a safe type (product $s$ ), a normal quality type (product $n$ ) and a problematic type (product $p$ ). The production cost for product $s$ is $C s$, that for product $p$ is $C p$; where $0<C p<C s<1$.

Refer to [12], according to the above-mentioned definition of Consumer's WTP for food safety, combining with dairy rigid demand characteristics, then consumer's WTP for product $s$ in percentage, i.e. WTPs is:

$$
\begin{aligned}
& \text { WTPs }=[(P s / P)-1] \times 100 \\
& \text { Then, } P s=(W T P s / 100+1) \times P
\end{aligned}
$$

where, the market price for product $s$ is $P$, which for product $n$ is $P$.

Assume enterprise $c$ plays different game strategy in different period of sales. The consumers don't know the diary products in the market are safe or not before public exposure of the problematic products by the government. In this period (called it the 1st game period, $t=1$. The game is just the enterprise $c$ 's game, as mentioned in part 1), all the diary products, whether they are produced by enterprise $h$ or enterprise $c$, are to be taken as product $s$. As above-mentioned, consumer expectation to food safety will affect the actual demand of safe diary 
products and their market price. So, the $P$ s in the first game period is adjusted as:

$$
P s_{1}=(\text { WTPs } / 100+1) \times P \times \rho
$$

where, the expectation of consumer to food safety of diary enterprises is $\rho(0<\rho<1)$. During a specific period, $\rho$ is stable and can be set as a constant.

So, before exposure of problematic products, the benefit $(B h)$ of enterprise $h$ who produces product $s$ is:

$$
B h_{1}=(W T P s / 100+1) \times P \times \rho-C s
$$

At the same time, the benefit $(B c)$ of enterprise $c$ who produces product $p$ is:

$$
B c_{1}=(W T P s / 100+1) \times P \times \rho-C p
$$

After supervision of government and exposure of problematic products by the government, combined with the above-said reputation mechanism based on Bayesian approach, the $P s$ in the second game period $(t=2)$ is:

$$
P s_{2}=\frac{(W T P S / 100+1) \times P \times \rho}{\rho+(1-\rho)(1-\gamma)}
$$

where, the exposure probability of problematic products in the market is $\gamma(0<\gamma<1)$. During a specific period, $\gamma$ is stable and can be set as a constant.

At this time, the benefit $(B h)$ of enterprise $h$ and the benefit $(B c)$ of enterprise $c$ are:

$$
\begin{gathered}
B h_{2}=P s_{2}-C_{s}=\frac{(W T P s / 100+1) \times P \times \rho}{\rho+(1-\rho)(1-\gamma)}-C_{s} \\
B c_{2}=(1-\gamma)\left(P s_{2}-C_{p}\right)=(1-\gamma)\left[\frac{(W T P s / 100+1) \times P \times \rho}{\rho+(1-\rho)(1-\gamma)}-C_{p}\right]
\end{gathered}
$$

During the $t$ game period $(t=1,2,3, \cdots, n)$, the $P s$ is :

$$
\left\{\begin{array}{l}
P s_{1}=(W T P s / 100+1) \times P \times \rho \\
P s_{t}=\frac{(W T P s / 100+1) \times P \times \rho}{\rho+\sum_{t=2}^{n}(1-\rho)(1-\gamma)^{n-1}} \quad(t=1)
\end{array} \quad(t=2,3, \cdots, n)\right.
$$

The benefit $(B h)$ of enterprise $h$ is:

$$
\left\{\begin{array}{lc}
B h_{1}=(W T P s / 100+1) \times P \times \rho-C s & (t=1) \\
B h_{t}=P s_{t}-C_{s}=\frac{(W T P s / 100+1) \times P \times \rho}{\rho+\sum_{t=2}^{n}(1-\rho)(1-\gamma)^{n-1}}-C_{s} & (t=2,3, \cdots, n)
\end{array}\right.
$$

The benefit $(B c)$ of enterprise $c$ is:

$$
\left\{\begin{array}{lc}
B c_{1}=(\text { WTPs } / 100+1) \times P \times \rho-C p & (t=1) \\
B c_{t}=(1-\gamma)\left(P s_{t}-C_{p}\right)=(1-\gamma)\left[\frac{(W T P s / 100+1) \times P \times \rho}{\rho+\sum_{t=2}^{n}(1-\rho)(1-\gamma)^{n-1}}-C_{p}\right. & (t=2,3, \cdots, n)
\end{array}\right.
$$

\section{Simulation}

Netlog, the programmable modeling software is used to perform multi-agent simulation. The agents include many enterprises of both types as enterprise $h$ and enterprise $c$ in diary industry. Figure 1 shows the simulation process and its inputs. 


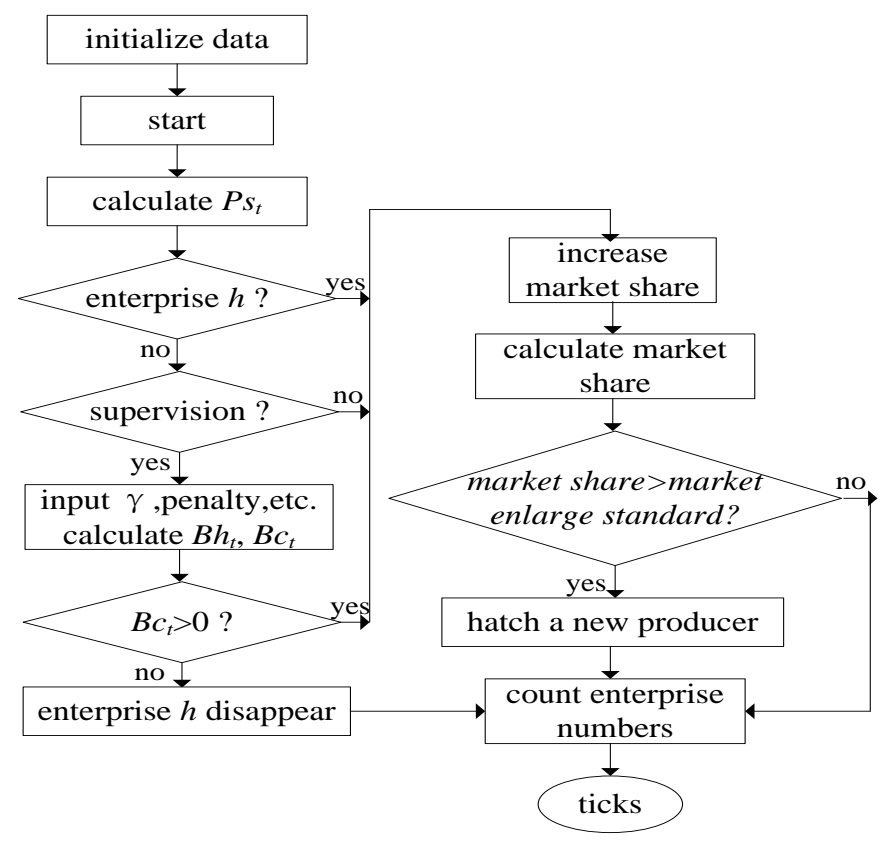

Figure 1. The simulation flowchart.

Initialized data which can be altered using slider controls in Netlog include:

-market capacity which is denoted by quantity of the products \& a certain number of dairy producers;

-exposure probability of problematic products in the market $\gamma$;

-penalties on exposure producers after supervision, etc.; the penalties refer to deprive of a certain amount of producer's profit, or compel them stop production \& sales for a certain period of time or mix the two modes.

The visual interface consists of an adjustable market with limited capacity. With reference to relative research papers in China, the initial data are set. The ultimate market capacity and number of dairy producers are 100,000 tons and 175 respectively [13]. According to survey of [12], $\rho=0.84$, the normal level of WTPs for safety food in diary industry is $14.82 \%$ and the high level of WTPs is $35 \%$. The producers sell milk powder in the dairy market and expanding their market share as "hatch" a new producer in simulation when they are large enough to an extent. When $B c<0$, the producer will "die" in Netlog.

The model verification procedure is just the same as [13]. After verification, the initial number of enterprise $h$ and enterprise $c$ are 22 and 87; market share and asset of enterprise $h$ and enterprise $c$ are the same as 10 units and 100 units respectively; $C p=3$ units; $C s=7$ units. All these initialization won't be changed otherwise mentioned whereafter.

Based on the afore-said background, we make the hypotheses as below.

Hypothesis 1: Only with reputation mechanism, without governmental supervision, the enterprise $h$ will increase faster than the enterprise $c$.

Hypothesis 2: Combined reputation mechanism with governmental supervision, the enterprise $h$ will increase obviously faster than the enterprise $c$.

\section{Simulation Results \& Discussion}

1) As for Hypothesis 1, when $\gamma=0$ (which means governmental supervision can't play a part), benefit of enterprise $h$ and enterprise $c$ is effected only by reputation mechanism, i.e. WTP $=14.82 \%$ and consumer expectation to food safety $\rho=0.84$. The number of enterprise $h$ is essentially unchanged, but the number of enterprise $c$ increase quickly (see Figure 2). When fixed the WTP, but adjusting the value $\rho$ from low to high, the shape of number of enterprise $h$ and enterprise $c$ just keep nearly the same as Figure 2. Hypothesis 1 has not passed the verification. This means that the reputation mechanism alone can't exert obvious influence to food safety. In Chinese actual dairy market, the fact is that despite food quality security accident occurred frequently, some of the large dairy enterprises still recovered their monopoly position soon due to the price rigidity, especially in 
mid- and low-end dairy market..

2) As for Hypothesis 2, WTP and $\rho$ are set as $14.82 \%$ and 0.84 respectively. After exposure of problematic products by the government, the fine will be 5 - 10 times of the value of problematic products sold in the market. Adjusting $\gamma$, exposure rate has obvious effect on numbers of enterprise $c$, even though the exposure rate is low (see Figure 3(a)). When $\gamma$ is increased to a extend, e.g. 0.45, within a relative long time, the enterprise $c$ will disappear completely (see Figure 3(b)). When $\gamma$ is large enough, e.g. 0.65, the number of enterprise $c$ decrease sharply (see Figure 3(c)) and even give enterprise $c$ no opportunity to survive as soon as they are exposed (see Figure 3(d)). Hypothesis 2 has passed the verification.

3) Based on Hypothesis 2, we set WTP $\gamma$ and $\rho$ are set as $14.82 \%, 0.70$ and 0.84 respectively. Adjusting the fine adopted on the enterprise $c$ after exposure. The lines of the number of enterprise $h$ and enterprise $c$ have similar change pattern as Figure 3, which means only high enough fine-even up to unimaginable high, which makes the enterprise $c$ bankrupt will bring about a credible environment for food industry.

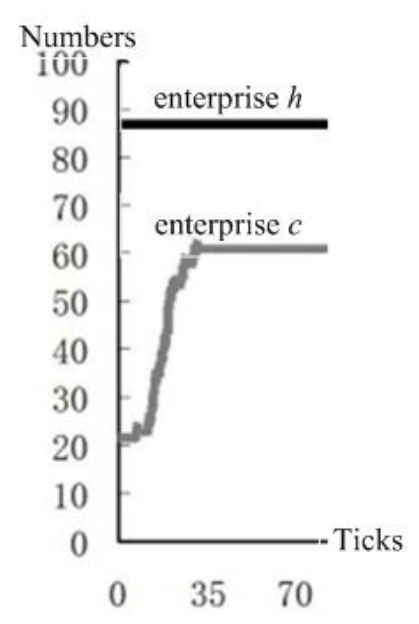

Figure 2. The number of enterprise $h$ and enterprise $c$ under Hypothesis 1.

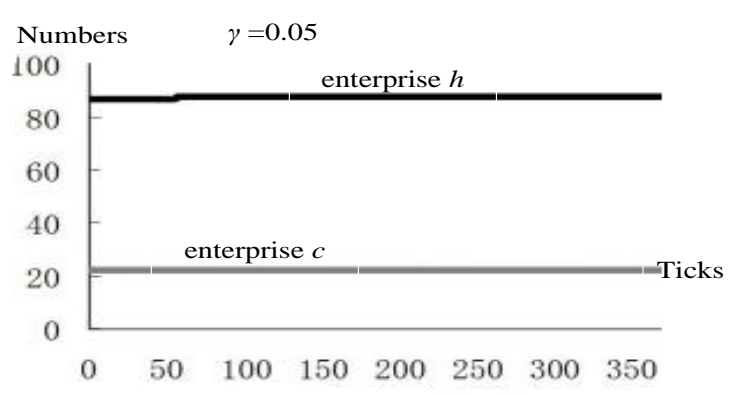

(a)

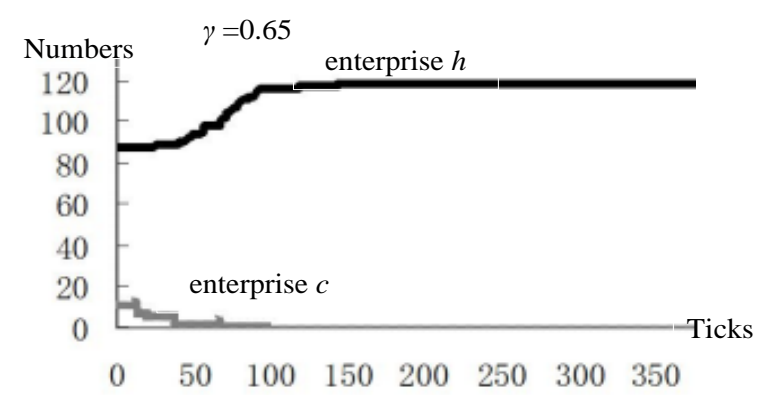

(c)

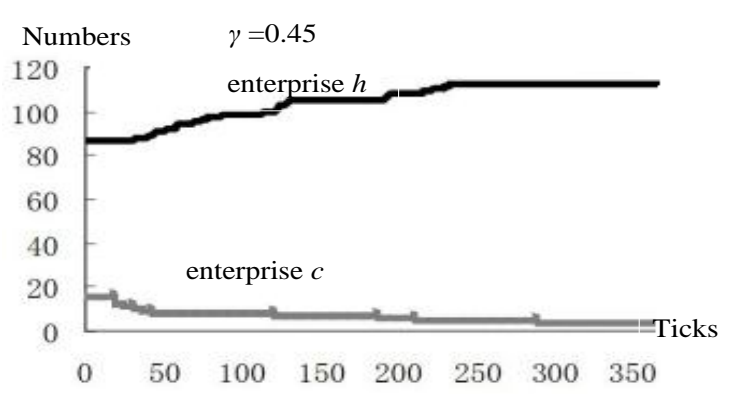

(b)

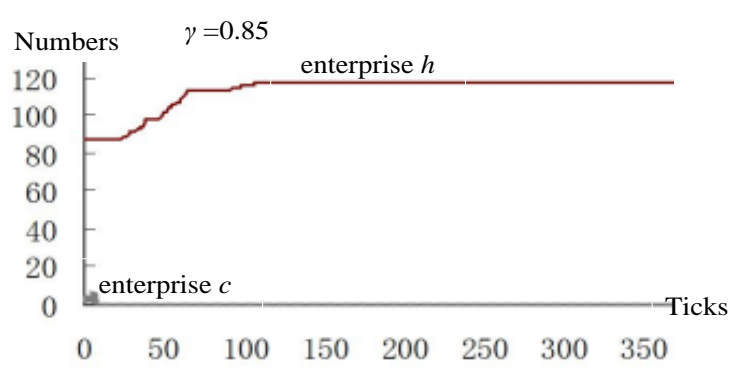

(d)

Figure 3. The number of enterprise $h$ and enterprise $c$ under Hypothesis 1. 


\section{Conclusions}

1) The reputation mechanism alone has little effect on food quality safety because of the price rigidity and monopoly market in mid- and low-end dairy market. Government should use laws and regulations measures to reduce market dysfunction and suppress industrial monopoly.

2) Combination reputation mechanism with governmental supervision has a good effect on food quality safety; especially it increases the exposure rate of problematic products or grants a high fine that makes the counterfeiters bankrupt.

\section{Acknowledgements}

This paper is an initial result of research sponsored by the Special Fund for Talents in Propaganda and Thought Field established by Guangdong Propaganda Department (Project No. XCWHRCZXSK2013-23) \& the National Social Science Fund of China (NSSFC) for Major Projects (14ZDA074).

\section{References}

[1] Anonym (2013) Research Report on Dairy Industry in 2013.

[2] Loader, R.J. and Hobbs, E. (1999) Strategic Responses to Food Safety Legislation. Food Policy, 24, 685-706. http://dx.doi.org/10.1016/S0306-9192(99)00073-1

[3] Ortega, D.L., Wang, H.H., Wu, L. and Olynk, N.J. (2011) Modeling Heterogeneityin Consumer Preferences for Select Food Safety Attributes in China. Food Policy, 36, 318-334. http://dx.doi.org/10.1016/j.foodpol.2010.11.030

[4] Wang, Z., Mao, Y. and Gale, F. (2008) Chinese Consumer Demand for Safety Attributes in Milk Products. Food Policy, 33, 27-36. http://dx.doi.org/10.1016/j.foodpol.2007.05.006

[5] Gall-Ely, M.L. (2009) Definition, Measurement and Determinants of the Consumer's Willingness to Pay: A Critical Synthesis and Directions for Further Research. Recherche et Applications en Marketing, 24, 91-113. http://dx.doi.org/10.1177/076737010902400205

[6] Clow, K.E. and Beisel, J.L. (1995) Managing Consumers Expectations of Low-Margin, High-Volume Services. Journal of Services Marketing, 9, 33-46. http://dx.doi.org/10.1108/08876049510079871

[7] Fouss, F., Achbany, Y. and Saerens, M. (2010) A Probabilistic Reputation Model Based on Transaction Ratings. Information Sciences, 180, 2095-2123. http://dx.doi.org/10.1016/j.ins.2010.01.020

[8] Akerlof, G. (1970) The Market for “Lemons”: Quality Uncertainty and the Market Mechanism. Quarterly Journal of Economics, 84, 488-500. http://dx.doi.org/10.2307/1879431

[9] Shapiro, C. (1983) Premiums for High Quality Products as Returns to Reputation. Quarterly Journal of Economics, 98, 659-680. http://dx.doi.org/10.2307/1881782

[10] Dellarocas, C. (2006) Reputation Mechanisms. In: Hendershott, T., Ed., Handbook on Economics and Information Systems, Elsevier Publishing, 629-660.

[11] Mui, L., Mohtashemi, M., et al. (2001) Ratings in Distributed Systems: A Bayesian Approach. Proceedings of the Workshop in Information Technologies and Systems, 2431-2439.

[12] Xing, W. (2007) Study on the Diary Quality Safety Management in China under Asymmetric Information Circumstances. Master's Dissertation, China Agricultural University.

[13] Chen, Y. and Li, Y. (2010) Simulation on Affects of Qualitative Supervision \& Management to Problematic Milk Powder. Advances in Systems Science and Applications, 10, 425-431. 